Article

\title{
Digital Holographic Interferometry for the Measurement of Symmetrical Temperature Fields in Liquids
}

\author{
Gramoz Cubreli ${ }^{1}$, Pavel Psota ${ }^{2, *}$, Petra Dančová ${ }^{1}$, Vít Lédl $^{2}$ and Tomáš Vít ${ }^{1}$ \\ 1 Faculty of Mechanical Engineering, Technical University of Liberec, Studentská 2, 46117 Liberec, \\ Czech Republic; gramoz.cubreli@tul.cz (G.C.); petra.dancova@tul.cz (P.D.); tomas.vit@tul.cz (T.V.) \\ 2 Faculty of Mechatronics, Informatics and Interdisciplinary Studies, Technical University of Liberec, \\ Studentská 2, 46117 Liberec, Czech Republic; vit.ledl@tul.cz \\ * Correspondence: pavel.psota@tul.cz
}

Citation: Cubreli, G.; Psota, P.;

Dančová, P.; Lédl, V.; Vít, T. Digital Holographic Interferometry for the Measurement of Symmetrical Temperature Fields in Liquids.

Photonics 2021, 8, 200.

https://doi.org/

10.3390/photonics 8060200

Received: 3 May 2021

Accepted: 2 June 2021

Published: 4 June 2021

Publisher's Note: MDPI stays neutral with regard to jurisdictional claims in published maps and institutional affiliations.

Copyright: (c) 2021 by the authors. Licensee MDPI, Basel, Switzerland. This article is an open access article distributed under the terms and conditions of the Creative Commons Attribution (CC BY) license (https:/ / creativecommons.org/licenses/by/ $4.0 /)$.

\begin{abstract}
In this paper, we present a method of quantitatively measuring in real-time the dynamic temperature field change and visualization of volumetric temperature fields generated by a $2 \mathrm{D}$ axial-symmetric heated fluid from a pulsatile jet in a water tank through off-axis digital holographic interferometry. A Mach-Zehnder interferometer on portable platform was built for the experimental investigation. The pulsatile jet was submerged in a water tank and fed with water with higher temperature. Tomographic approach was used to reconstruct the temperature fields through the Abel Transform and the filtered back-projection. Averaged results, tomographic view, standard deviation and errors are presented. The presented results reveal digital holographic interferometry as a powerful technique to visualize temperature fields in flowing liquids and gases.
\end{abstract}

Keywords: digital holographic interferometry; pulsatile jets; temperature fields; Mach-Zehnder interferometer; tomography

\section{Introduction}

The wide range of applications of liquids and determining their properties, especially the temperature changes within the working fluid, play a key role in many sectors of industry and research. Depending on the application, determining such temperature changes can be a crucial step in determining the end-result and efficiency of the process. For this reason, determining temperature changes through non-contact, non-destructive optical methods is very convenient.

Non-contact and non-destructive optical interferometric methods have found a wide range of applications. The discovery of the wave property of light by Thomas Young with its double slit experiment and the interference phenomenon opened up an entire range of possible applications based on the wavefront comparison involving the interference of wavefronts, providing full-field refractive index data to evaluate temperature profile [1,2]. Digital holographic interferometry (DHI) stands as one of these methods, and it is considered as belonging to the group of the most accurate methods [3]. Combining high sensitivity and flexibility, this method is attractive to be used for research. Moreover, the digital acquisition of data allows for data processing and numerical propagation of the wavefield to any plane of interest [4]. The direct phase retrieval and its differential nature, make digital holographic interferometry an attractive tool for the study of heat transfer phenomena [5]. It also provides high spatial and temporal resolution and with automation of the recording and reconstruction process, real time visualization is possible $[6,7]$.

There is a vast field of applications of DHI and other interference based methods including: entertainment display [8], imaging heat transfer and mass transfer [7,9-13], research in free convection [14,15], visualization of the 3D velocity vector field in turbulent boundary layer [6], analysis of supersonic jets [6], biological (living cell imaging) [6,16], environmental applications $[6,17]$, precision measurements [8,18,19], small displacements [20], 
thermomechanical analysis and non-destructive testing [6], microscopy and high-resolution volume imagery [21,22], vibrometry [23,24], topography [25,26], process monitoring [7], computerized tomography $[7,27]$, and so on.

This paper aims at investigating heat transfer problems. The amplitude of the propagating object wave through the transparent media is not significantly affected, while the phase of an optical wave is [5]. DHI is sensitive to the optical phase change and thus can be advantageously used for investigation of this kind of problem. However, as the optical phase is integrated along the optical path, the calculation of the quantity under investigation must be performed with regard to the nature of the physical field that we measure. Three categories of physical fields can be considered:

- Two-dimensional temperature field (temperature varies only in one direction);

- Symmetrical temperature field (temperature is a function of radius only);

- Asymmetrical temperature field (general temperature distribution);

Two-dimensional [5,10,28-30] and purely symmetrical [31-33] fields can be measured by one arm interferometer, only the data processing differs for each category.

Examination of asymmetric fields [34-36] could not be generally done without the use of cumbersome tomographic approach. The tomographic approach requires a large number of different projections of the measured field. It is either necessary to use many interferometer arms and many digital sensors in the measurement setup to obtain digital holograms for different viewing directions or the problem could be solved having only one digital sensor and a rotating stage. Rotation of the object is applicable only for steady or periodical coherent (self-similar in each cycle) phenomenon. Very often the tomographic approach cannot be realized due to the mentioned physical limits or technical issues as rotating of the object (particularly for heavy system in liquids) or building multiple-arm interferometer might be very challenging. However, in practice, we often encounter quasisymmetric fields. Pulsatile jets (PJ) with symmetrical openings are a good example. Such a stream of fluid is represented by the time-mean, periodic (symmetrical) and fluctuating random part, of which the periodic part is of the main interest. Moreover, so far, little effort has been made into the pulsatile jets (PJ) study in liquids, which is more challenging than PJ investigation in gases. Some other phenomena in fluids using DHI have been investigated [37-39]. In this paper, we present a single-shot DHI technique suitable for the investigation of quasi-symmetric PJ in fluids, including uncertainty analysis.

\section{Pulsatile Jets}

In fluid dynamics, a jet is defined as a stream of fluid that is projected through an opening under pressure into a surrounding medium [40].

When a fluid flows out of the free openings or other outlets into free space, a free jet forms. Based on viscosity, the particles from the surroundings are entrained into the main stream. By absorbing a portion of the jet's power, the particles play a role in slowing it. With distance, the velocity of the fluid decreases and the jet expands [41].

A pulsatile jet in the other hand, is a fluid jet generated from fluid oscillations during a periodical fluid exchange between an actuator cavity and surrounding fluid [42].

Pulsatile jets have a zero-net-mass-flux. This is due to the fact that pulsatile jets suck in the working fluid from the environment and eject it at the end. On the other hand, they allow momentum transfer to the flow. This comes from the asymmetry of the flow conditions across the orifice. By generating vortices in some operational conditions, flow dynamics of the external flow far from the orifice can be affected. Pulsatile jets are inherently pulsatile and periodic, and they can be produced in a number of ways through the use of piezoelectric, electromagnetic (e.g., solenoids), acoustic (e.g., speakers), or mechanical (piston) drivers [43,44].

A meaningful advantage of PJs is a relative simplicity of an arrangement: neither blower nor fluid supply piping is required, and only a small electrical power input is needed. This makes jets efficient and attractive [42-44]. 
Applications of pulsatile jets are numerous: improved fluid mixing and higher heat transfer coefficients have been demonstrated in electronic cooling applications using pulsatile jets [45], applications in flow control in external aerodynamics [46], in supersonic aircraft [47], drag reduction improvement in space aircraft [48], for cooling [49,50], etc.

A typical PJ (Figure 1) actuator consists of a cavity with an oscillating wall (diaphragm or piston). Mechanical energy is transferred from a transducer via oscillating wall to the fluid. The transducer can be arranged either separately from the actuator or it can be integrated into the cavity [42].

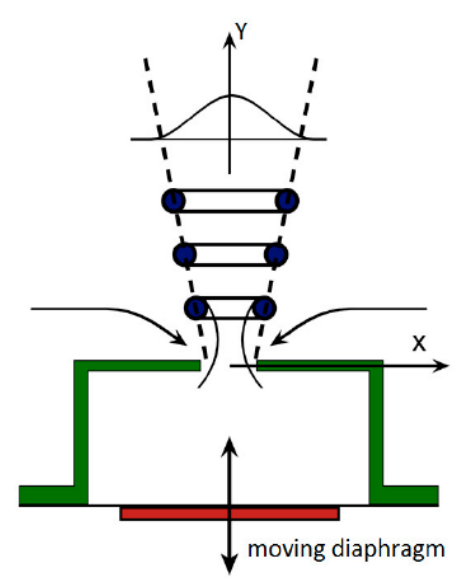

Figure 1. Schematic of a pulsatile jet [51].

The jet profile after ejections consists of mainly three regions [52]:

(I) The initial region,

(II) The transition region,

(III) The region of the fully developed jet.

\section{Off-Axis Digital Holographic Interferometry}

Digital holographic interferometry is a non-contact, non-invasive, whole-field, differential, and highly accurate experimental method for measuring quantities that affect the phase of a light wave passing through or reflected from the measured object [28,51].

The hologram is recorded by a camera and the reconstruction is done by numerical methods, by multiplying the digital holograms with the complex amplitude of the reference wave.

In optics, the temperature change is measured via measuring the change of optical properties of the phenomenon under investigation that is caused by such a temperature gradient. Heat and mass transfer problems are specific by the fact that the amplitude of the object wave is not significantly affected while passing through the testing subject, while the phase is very sensitive to such effects. The relative change in the refractive index of the medium that is subjected to thermal gradients with respect to that of the ambient medium have been correlated with the retrieved phase distribution through [53]:

$$
\Delta \varphi=\frac{2 \pi}{\lambda} \int_{L} \Delta n d l,
$$

where $\Delta n$ is the change of the refractive index between the actual state and the referential state and $d l$ represents the differential distance along the propagation line $L$. This allows for direct access to the phase. In general, the refractive index distribution can be classified as: flat (refractive index is constant along the optical axis), symmetrical or asymmetrical. 
For axially symmetric temperature fields, the relation between the refractive index and the phase can be calculated by making use of the Abel transform:

$$
\Delta \varphi=\frac{4 \pi}{\lambda} \int_{-\infty}^{\infty} \frac{r \Delta n}{\sqrt{r^{2}-x^{2}}} d r .
$$

To calculate the temperature, the change of refractive index for temperature must be known. For the case of water, $\frac{d n}{d T}$ for $\lambda=632.8 \mathrm{~nm}$ was determined [53] as:

$$
\frac{d n}{d T}=-0.985 \times 10^{-4}
$$

The link between the temporal change of temperature $\Delta T$ (between the moment of measurement and the reference state temperature at $t=0 \mathrm{~s}$ ) and the phase change $\Delta \varphi$ is given as:

$$
\Delta T=\frac{\lambda}{2 \pi} \frac{\Delta \varphi}{L \cdot \frac{d n}{d T}} .
$$

The temperature can finally be computed as:

$$
T(t)=T(0)+\Delta T(t),
$$

where $T(0)$ is the ambient fluid temperature at the reference state.

The off-axis spatial intensity interference pattern distribution coming from the interference of the reference and the object wave that hit the camera at any given spatial coordinate $(x, y)$ at an angle $\theta$ introduces spatial carrier frequencies $v_{C x}$ and $v_{C y}$, giving rise to a denser interference pattern which can be mathematically expressed as:

$$
\begin{gathered}
h(x, y)=\left|U_{r}+U_{o}\right|^{2}=\underbrace{\left|U_{r}\right|^{2}+\left|U_{o}\right|^{2}}_{0^{\text {th }} \text { order of diffraction }}+\underbrace{U_{r} U_{o}{ }^{*}}_{+1 \text { st order }}+\underbrace{U_{r}{ }^{*} U_{o}}_{-1 \text { st order }}= \\
=A(x, y)+B(x, y) \cos \left(\varphi(x, y)+2 \pi v_{C x} x+2 \pi v_{C y} y\right),
\end{gathered}
$$

where $U_{r}$ represents the reference wave, $U_{o}$ the object wave, $A$ represents the additional component (the background intensity), $B$ the multiplicative term (modulation intensity), and $\varphi$ the phase difference between the two arms of the interferometer. Both of the last terms contain the same information, but are conjugate to each other. Therefore, the +1 st term should be selected. The interference phase is coded in a cosine modulated fringe pattern. The accuracy with which the quantity of interest can be determined, depends on the phase retrieval method [15]. By applying the Fourier Transform and making use of its properties, the equation now is:

$F T\{h(x, y)\}=\hat{h}\left(v_{x}, v_{y}\right)=\hat{A}\left(v_{x}, v_{y}\right)+\hat{C}\left(v_{x}-v_{C x}, v_{y}-v_{C y}\right)+\hat{C}^{*}\left(v_{x}+v_{C x}, v_{y}+v_{C y}\right)$,

where $\left(v_{x}, v_{y}\right)$ represent the spatial frequency coordinates, $\left(v_{C x}, v_{C y}\right)$ the spatial frequencies that arise from the tilt. The roof symbol` denotes Fourier spectrum. By adjusting the tilt angle between the reference and object wave, both of these three terms can be well separated in the Fourier domain to minimize their overlapping, thus determining the carrier frequencies. The specific order of diffraction can be extracted by means of bandwidth-limited filtering around the specific spatial frequencies. The remaining spectrum $\hat{C}\left(v_{x}-v_{C x}, v_{y}-v_{C y}\right)$ is no longer Hermitean, so the inverse FT applied gives a complex field $D(x, y)=C(x, y) e^{j\left(2 \pi v_{x} x+2 \pi v_{y} y\right)}$ with non-vanishing real and imaginary parts.

The carrier frequencies $v_{C x}$ and $v_{C y}$ are set in order to correctly separate all spectral components while at the same time respecting the Nyquist sampling criterion through a 
small tilt in between the object and the reference wave. The maximum angle $\theta_{\max }$ between the two interfering waves is expressed as:

$$
\theta_{\max }=2 \arcsin \left(\frac{\lambda}{4 \Delta \xi}\right) \approx \frac{\lambda}{2 \Delta \xi^{\prime}}
$$

while the maximum frequency is limited by the Nyquist frequency $v_{N}$, which is defined by the digital sensor pixel extension $\Delta \xi$ as $v_{N}=1 / 2 \Delta \xi$.

The spectral bandwidth $v_{B}$ of $\hat{C}\left(v_{x}-v_{C x}, v_{y}-v_{C y}\right)$ reflects the slope of the interference phase $\phi: v_{B} \approx \nabla \phi$, where $\nabla$ denotes the gradient. $v_{B}$ influences the size of the applied bandpass filter window and optimal value of carrier frequencies. It is important to note that the spectral bandwidth $v_{B}$ cannot exceed the spatial-frequency bandwidth of the pixelated digital sensor.

The complex field $D(x, y)$ represents an optical field at a certain initial plane. In the case of lensless DHI, the optical field $D$ is associated to the object plane while for image plane $\mathrm{DH}$ (using lens to image the object), $D(x, y)$ stands for the image plane. Using diffraction theory, one can propagate optical fields from object to image plane (lensless DHI) or focus around the image plane (image plane DHI). Diffraction theory describes the propagation of optical fields and allows for the numerical reconstruction of images which are each described by its intensity and phase. Complex optical fields in the image plane $U_{i}$ are calculated using the Sommerfeld formula, which decribes the diffraction of light at distance $d$ from the initial plane. The Sommerfeld integral can be solved by Fresnel approximation which in the discrete finite form is expressed as [53]:

$U_{i}(n \Delta x, m \Delta y)=\frac{e^{-j \frac{2 \pi}{\lambda} d}}{\lambda d} \sum_{k=1}^{N} \sum_{l=1}^{M} D(k \Delta \xi, l \Delta \eta) \cdot r^{*}(k \Delta \xi, l \Delta \eta) \cdot e^{j} \frac{\pi}{\lambda d}\left[(k \Delta \xi)^{2}+(l \Delta \eta)^{2}\right] e^{-j 2 \pi\left(\frac{k n}{N}+\frac{l m}{M}\right)}$,

where $j=\sqrt{-1}, n=1, \ldots, N$ and $m=1, \ldots, M$ represents the pixels of the camera, and $d$ is the distance of the phase object from the sensor of the camera. The stored holograms have $N \times M$ discrete values, with pixel distances $\Delta \xi$ and $\Delta \eta$, with physical size of the recording area of the camera to be $N \Delta \xi \times M \Delta \eta$. $r^{*}$ represents the conjugated of discrete numerical reference wave, which is used for the reconstruction of the sharp real image at distance $d$. By digitally reconstructing the diffracted field, we have direct access to the amplitude image and the phase image [6]:

$$
I_{i}(n, m)=\left|U_{i}(n, m)\right|^{2}, \varphi_{i}(n, m)=\arctan \left(\frac{\operatorname{Im}\left\{U_{i}(n, m)\right\}}{\operatorname{Re}\left\{U_{i}(n, m)\right\}}\right) .
$$

The phase of the field is calculated using the arctangent function, and consequently, the result will be contained within the interval $[-\pi,+\pi]$, i.e., modulo $2 \pi$. In the case of image plane DHI, when the image is formed directly on the digital sensor, $U_{i}$ in (10) can be replaced directly by the complex field $D$.

The phase $\varphi$ is affected by any aberrations of the optical system and thus it is usually not of the main concern. In DHI, firstly a digital hologram for the reference state (i.e., no phenomenon) is captured and processed as aforementioned in order to retrieve the phase denoted as $\varphi_{R}$. In further steps, digital holograms during a phenomenon under investigation occurrence are captured and processed leading to phase fields $\varphi_{M}$. The interference phase $\Delta \varphi$ showing only the measured phenomenon can then be determined in a pointwise manner by a modulo of $2 \pi$ substraction [53]:

$$
\Delta \varphi=\left\{\begin{array}{cc}
\varphi_{M}-\varphi_{R} & \text { if } \varphi_{M} \geq \varphi_{R} \\
M-\varphi_{R}+2 \pi & \text { if } \varphi_{M}<\varphi_{R}
\end{array} .\right.
$$

The estimation of the optical phase of the reconstructed field is key to a large number of applications in digital holography [6]. The possibility of direct access to the phase difference information is one of the major advantages of digital holographic interferometry [5]. 


\section{Tomographic Reconstruction}

Tomography is generally a non-invasive imaging technique. It allows for visualization of internal structures without the superposition of over- and under-lying structures [29]. As said previously, the refractive index distribution can be generally classified into three groups in regard of its distribution: flat, symmetrical, and asymmetrical. The first two represent the simplest case and the easiest to reconstruct the temperature fields.

Tomography in general involves two steps: the recording of the projection data and the reconstruction of the original data that was projected. Projections from many angles in order to be able to faithfully reconstruct the real temperature field are required. The more projections there are, the more exact and reliable the reconstruction will be. This undoubtfully makes the setup more complex and the need of a superfast camera is a must. The recording is done by digital cameras and the captured images represent the projection of the 3D object into 2D images. Although for the case of periodically self-similar repetitive phenomena, only one superfast camera can be used, by changing the angle of recording for each period of the phenomena (by a rotating stage) and synchronizing the recording with the period of repetition. Noise and errors are suppressed by averaging the images with the same phase in different periods.

For axi-symmetrical cases, the procedure is simplified. The tomographic approach makes use of the Abel Transform. The representation of the data obtained by Abel Transform as a function of the angle of projection is called a sinogram. It contains the data from the projection for different angles stored as columns. By applying a filter to suppress some range of oversampled low frequencies in the Fourier domain and a window in order to prevent possible numerical Fourier Transform issues, we obtain what is known as the inverse Abel Transform with filtered back-projection:

$$
\Delta n(x, y)=\frac{\lambda}{2 \pi} \int_{0}^{\pi} \int_{-\infty}^{\infty} \Delta \varphi(s, \theta) \cdot b(x \cos \theta+y \sin \theta-s) d s d \theta,
$$

where $b$ represents a filter and a window. It expresses the filtered back-projected image for all angles, which are smeared out in space. The filtered back-projection is an analytical method that propagates the sinograms into space for all angles along specific projection paths in order to reconstruct the $3 \mathrm{D}$ profile.

\section{Materials and Methods}

Figure 2 shows a schematic of the holographic setup that was implemented for this study. The setup consists of two portable parts, made for easier transportation and a more compact setup. It is based on the Mach-Zehnder interferometer, which gives as output the interference pattern that is dependent on the refractive index change occurring in the phase object (OBJ). A Mach-Zehnder interferometer consists of two interferometric arms, the object arm and the reference arm. After passing through a fibre-beamsplitter (FS), the laser beam is split into two. The first beam acts as the object wave that passes through the phase object under investigation, while the other beam acts as the reference wave. The object beam is collimated into a parallel beam by a collimator $(\mathrm{L})$ before passing through the water tank containing the pulsatile jet. Before impinging the camera, the object wave passes through lenses L1 and L2, which act as a $0.12 \times$ beam expander in order to reduce the beam diameter to fit the digital sensor size. Both waves are recombined and superimposed by a non-polarizing beamsplitter (NBS), collimated by a lens (L2) and redirected to the digital camera (CAM) where the microinterference pattern is electronically recorded for further processing. The reference wave was aligned with the object wave by positioning of the fiber output aiming to NBS. The angle between both waves was set by analyzing the Fourier spectrum in real time. The adjustment of both waves intensities has been made for the highest fringe contrast value possible. A highly coherent helium-neon laser (LAS) of wavelength $\lambda=633 \mathrm{~nm}$ with maximal output optical power of $50 \mathrm{~mW}$ has been employed for this study. Since holographic interferometry is very sensitive, the optical setup has been put on a vibration-isolated optical table. 


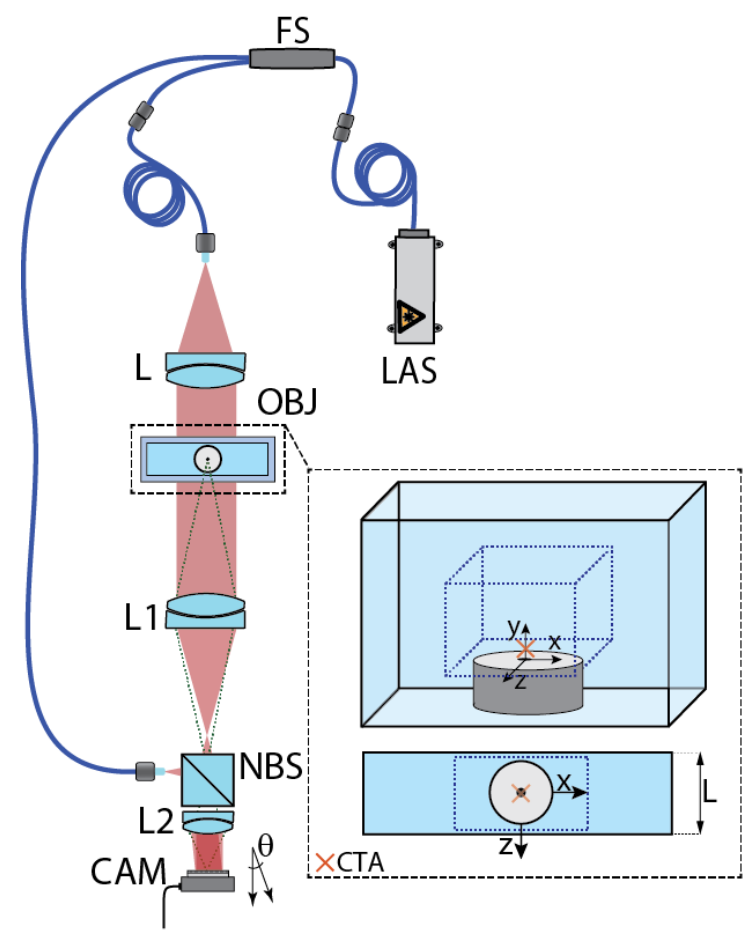

Figure 2. Schematic of the Mach-Zehnder optical setup.

The used camera is a UI-3370CP Rev. 2, $2048 \times 2048$ pixel, $5.50 \mu \mathrm{m}$ pixel size CMOS camera.

The field of view of the measured area was $92.1 \times 92.1 \mathrm{~mm}^{2}$.

The object under study is a pulsatile jet (PJ) with a circular opening of $4 \mathrm{~mm}$, submerged in a water tank containing water at temperature of $T_{0}=17^{\circ} \mathrm{C}$. The pulsatile jet is fed with prewarmed water, the temperature of which was predetermined to be around $33{ }^{\circ} \mathrm{C}$. The warm water passes through the orifice to create the jet profile. Time period of the PJ is $5 \mathrm{~s}$, i.e., long enough for the flow to get steady. The PJ period therefore consists of the initial transient stage, steady stage, and final transient stage. The long period phenomenon with a steady flow was chosen on purpose in order to separate random and steady component of the PJ. The inner dimensions of the glass water tank are $(x, y, z) 31 \mathrm{~cm} \times 31 \mathrm{~cm} \times 11 \mathrm{~cm}$ with wall thickness of $5 \mathrm{~mm}$ and has been filled with water up to the height of $h=24 \mathrm{~cm}$.

In the first step, all holograms have been recorded and reconstructed by the Equation (9). In total, 314 holograms have been recorded, with some being captured when the system was off and later used as the reference. Example of a hologram is shown in Figure 3. They have been captured with framerate of $7.67 \mathrm{fps}$ and sampling time of $0.1304 \mathrm{~s}$.

Figure $3 \mathrm{~b}$ shows the Fourier domain of the reference hologram. Here, the term $\hat{C}\left(v_{x}-v_{C x}, v_{x}+v_{C y}\right)$ can clearly be seen separated from the terms $\hat{A}\left(v_{x}, v_{y}\right)$ and $\hat{C}^{*}\left(v_{x}+v_{C x}, v_{y}+v_{C y}\right)$ due to the tilt between the reference wave and the object wave, from which the carrier frequencies $v_{C x}$ and $v_{C y}$ were introduced by real time observation of the Fourier spectrum while adjusting the reference arm of the interferometer. In order to avoid phase errors from diffraction effects, the angle has been selected to be slightly greater. The choice of the carrier frequencies depends on various factors, as the Nyquist criteria, distance from the detector and its size, and importantly the gradient of phase $\nabla \varphi$. The gradient of phase $\nabla \varphi$, i.e., object wavefront curvature, is high due to the "lensing" effect of the water tank. The digital sensor's spatial-frequency bandwidth was sufficient in order to cover the spectral bandwidth $v_{B}$ of $\hat{C}$ and the spatial carrier frequencies were adjusted in order to avoid overlapping in the Fourier spectrum. The carrier frequencies were determined to be $v_{C x}=123 \mathrm{~mm}^{-1}$ and $v_{C y}=-157 \mathrm{~mm}^{-1}$. This allows for the determination of the tilt angle between both waves with respect to the direction of propagation $z$ to be $\alpha_{x} \approx \lambda v_{C x}=4.45^{\circ}$ 
and $\alpha_{y} \approx \lambda v_{C y}=5.68^{\circ}$. A 2D Hanning window with a bandwidth of $v_{B}=200 \mathrm{~mm}^{-1}$ and centers $v_{C x}=123 \mathrm{~mm}^{-1}, v_{C y}=-157 \mathrm{~mm}^{-1}$,corresponding to the carrier frequencies that have been applied in order to filter the term out, was used in order to retrieve the complex field in Equation (7).

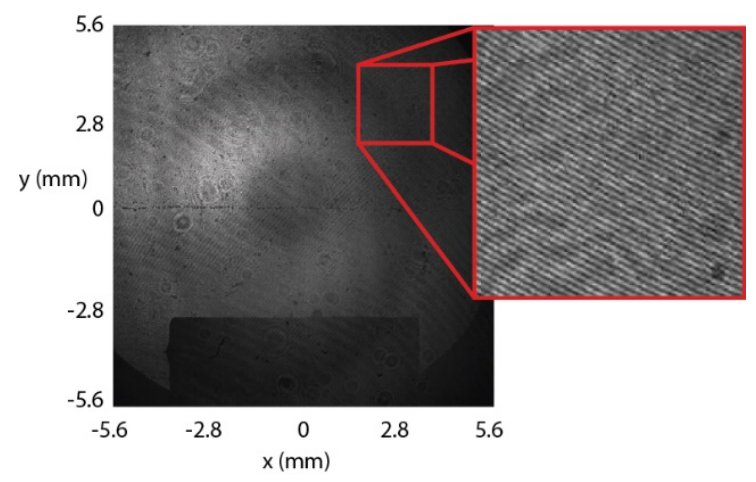

(a)

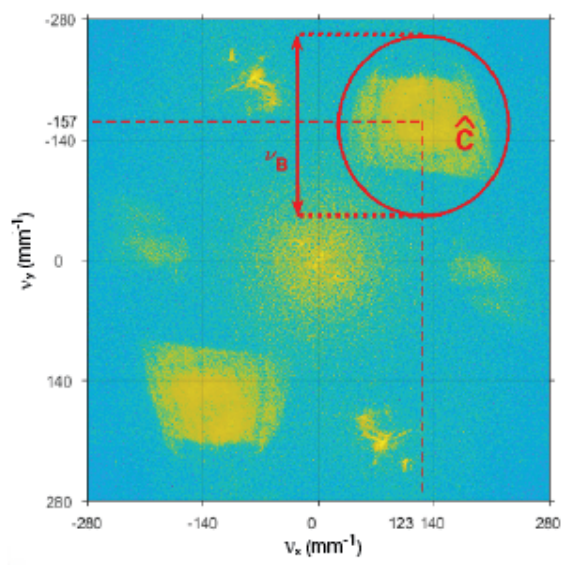

(b)

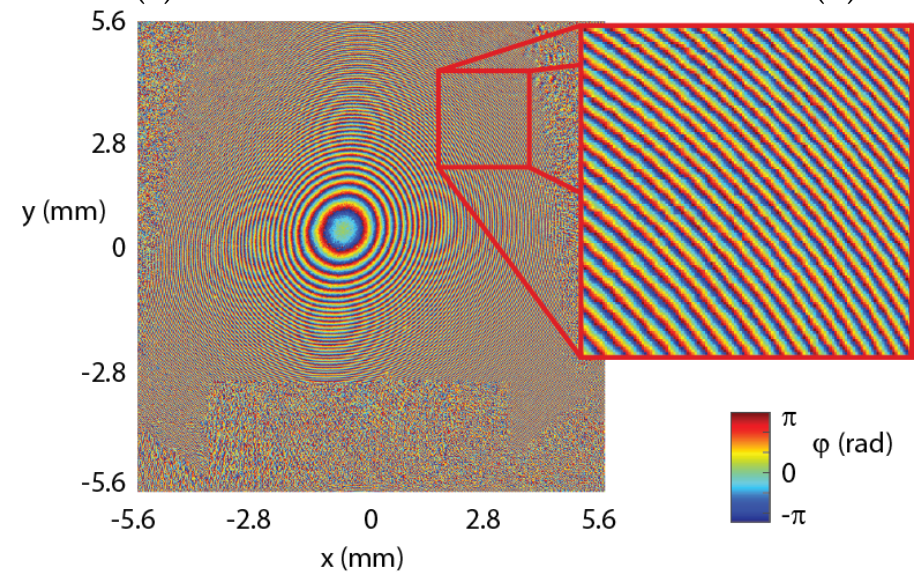

(c)

Figure 3. (a) Interferogram at $t=0 \mathrm{~s}$ (reference state), (b) magnitude in logarithmic scale of the in-terferogram's FT spectra with the denoted term $\hat{C}\left(v_{x}, v_{y}\right)$, (c) the wrapped phase computed from $\hat{C}\left(v_{x}, v_{y}\right)$.

The same procedure is applied to all digital holograms. It is important to note that the filtering window remains unchanged for all holograms. The interference phase between a hologram captured at time $t$ with respect of the reference hologram has been calculated as modulo of $2 \pi$ (11). The wrapped interference phase distributions were free of undersampled areas and therefore has been successfully unwrapped through the Goldstein algorithm [54]. The process of unwrapping introduces itself error uncertainty. Mostly, these uncertainties are too small to be taken in consideration. Phase aberrations are present, apart from the dynamic phase change from the measured phenomena, in both the reference and the object beam along the whole optical path. Phase aberrations can come from different contributors, such as the improper selection of carrier frequencies, tilt between the reference and object wave, imperfections in the optical components or the misalignment of the optomechanical components of the interferometers. The filled water tank in steady state introduces significant wavefront error. Figure $3 \mathrm{c}$ illustrates the phase aberration from the combined wavefront hitting the sensor of the camera. Since these aberrations are stationary (time invariant) and come from the optical system, in case of digital holographic interferometry where the phase fields are compared to the reference state that carries the same phase field aberration, these aberrations vanish from calculation. This is one advantage of 
this technique, since all imperfections in the optomechanical elements become less relevant and carrier frequencies do not have to be precisely set. Therefore, the state reference has been captured shortly before the exhibition of the phenomena of interest.

Since we deal with the case of symmetrical orifice, we assume the development of a symmetric temperature field. Based on this assumption, only capturing one projection for the analysis is supposed to be sufficient in order to retrieve the refractive index field in Equation (2).

The temperature field has been retrieved by using the inverse Abel Transform. This was done by taking one row of the phase data and reconstructing the slice. The reconstruction of the 2D plan sliced has been done by the filtered back-projection method, which later were all stacked on top of each other to form the 3D temperature profile.

In real experiment, steady (symmetrical) and random components of the flow occur. Within the middle stage of the PJ period when the PJ flow is laminar, we separated the steady (symmetrical) and random flow components using averaging of phase maps at different time instants. This reveals how valid the assumption about the symmetrical flow is.

\section{Results}

The results from the interferometry-based visualization of temperature fields from a jet with warm water have been discussed here. Some of the illustrated results are restricted only to the relevant regions for study and are a projection of the testing subject, hence they are predominantly two-dimensional and averaged along the optical path. Three dimensional reconstructions are also presented.

Temperature values measured through off-axis digital holographic interferometry are relative, meaning that a starting point must be a priori known. The temperature of the water in the tank has been measured right before the experiment started with a thermometer and is assumed to be only slowly varying at the edge of the digital camera field of view. The temperature has been computed using Equation (5).

Phase and temperature values are displayed according to the color bar legends located on the side of the results. In the case of $2 \mathrm{D}$ visualization, displayed values must be understood as averaged values along the optical propagation path.

Figure 4 shows the symmetrical whole-field interference phase profile of warm water flowing out from a single circular orifice with a diameter of $4 \mathrm{~mm}$ from the orifice at two different instants of time. Three cross sections were drawn for analysis. It shows the effect of temperature on the refractive index of water at the three cross sections, which are plotted in the graphs right next to them. As expected, the phase is lower at the vicinity of the orifice where the warm water comes out and the phase change is less at the distance where the warm water mixes with the colder water. The time instants were chosen when the jet profile was the most stable. 

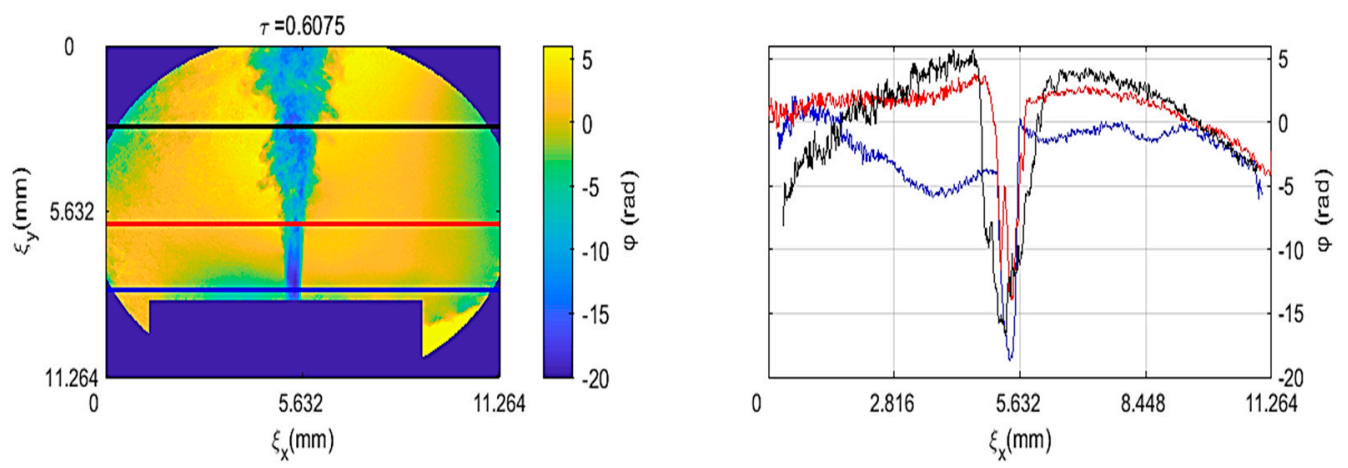

(a)
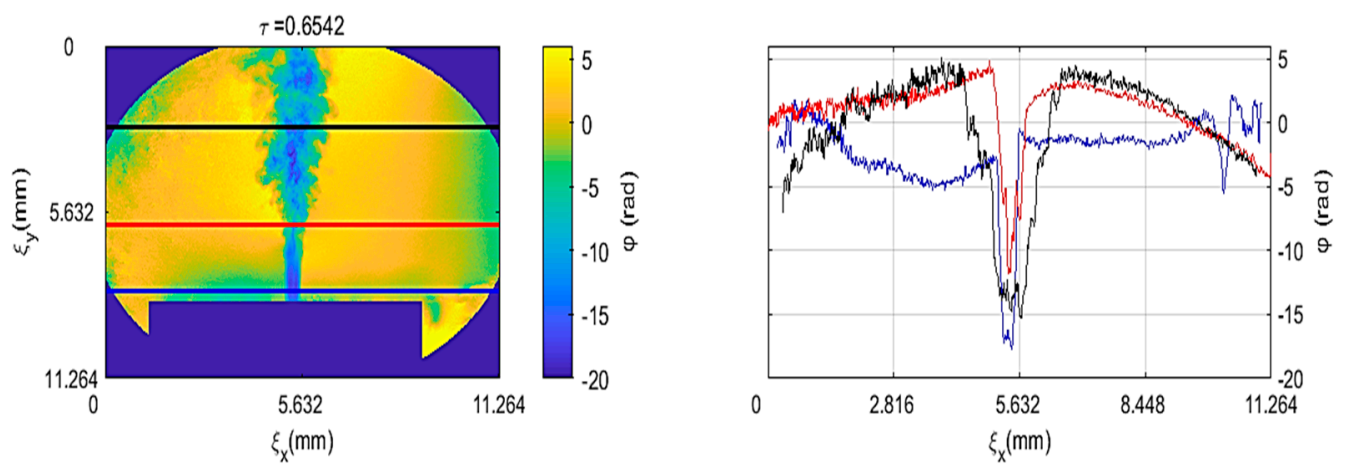

(b)

Figure 4. (a,b) Whole-field interference phase profile of warm water flowing out from a single circular orifice and its plot at two different relative instants.

Figure 5 shows the time development of the phase profile of the jet stream coming out of the orifice. Several points in time have been selected to show the formation of the characteristic jet profile and its development in time. The first row shows the beginning when warm water starts flowing under pressure. The jet profile can be seen clearly established on the second row. On the last row, after stopping the incoming warmer water, a small pocket of warm water can be seen moving upwards. Digital holographic interferometry can clearly visualize the PJ position and evolution and track its movement in space and time. Retrieved phase distributions and characteristics of PJs deduced from them are valid regardless of the kind of measured phenomenon. However, in order to quantitatively retrieve refractive index distribution and hence temperature field distribution, the phase fields are assumed to be symmetrical. This assumption introduces some uncertainty, as discussed further in the text.

Figure 6 shows the 3D reconstruction using inverse Abel transform of the jet profile at three different instants in time. The first one depicts the 3D reconstruction of the jet profile, while the two consecutive ones depict the reconstruction of the small warm water pocket. Tracking can be done from frame to frame. 


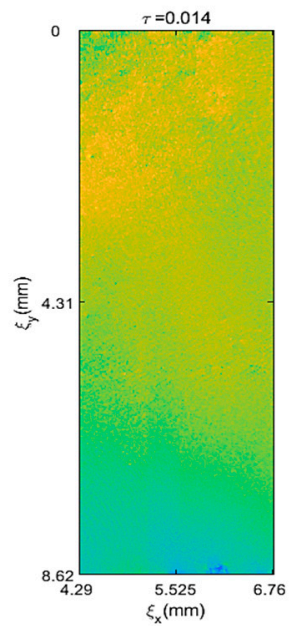

(a)

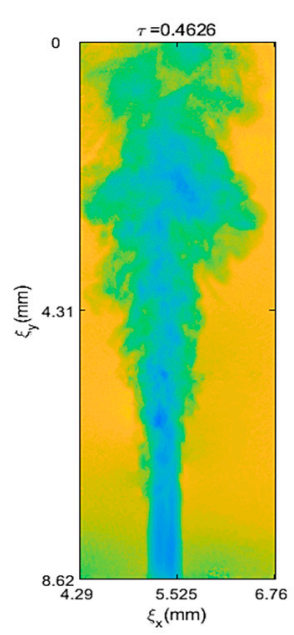

(f)

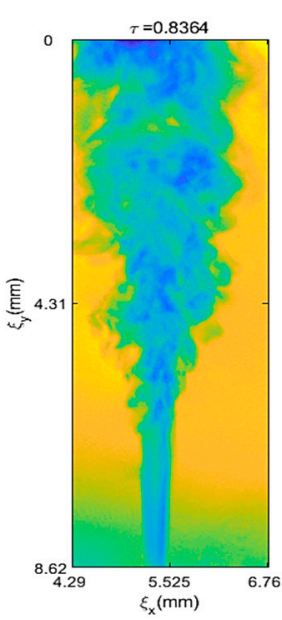

(k)

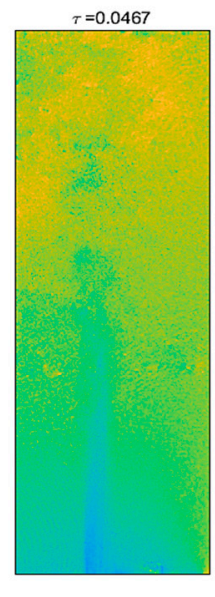

(b)

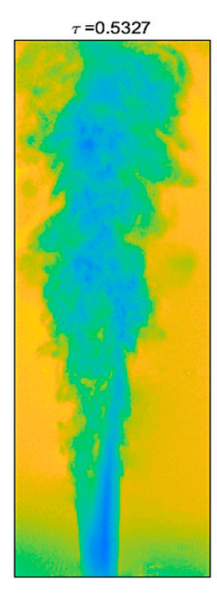

(g)

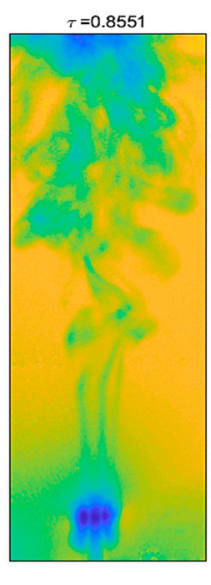

(1)

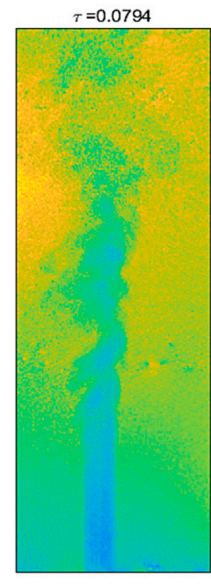

(c)

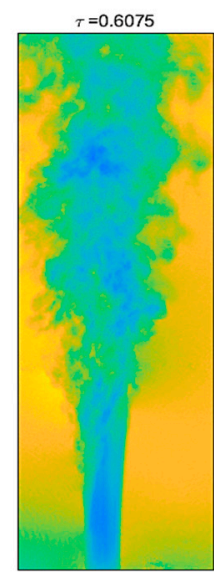

(h)

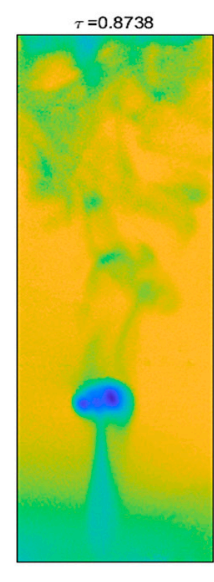

(m)

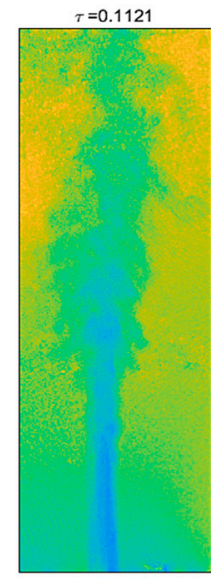

(d)

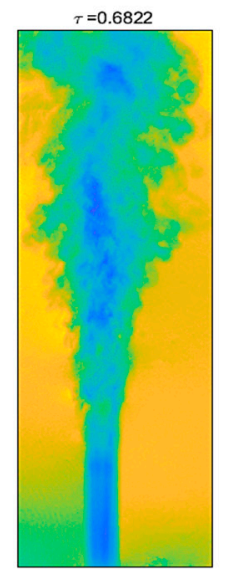

(i)

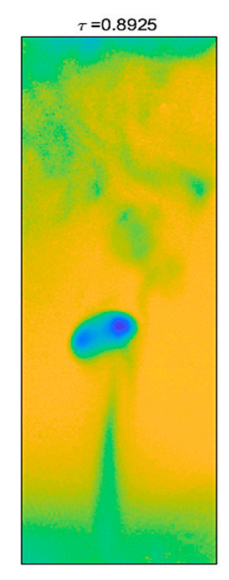

(n)

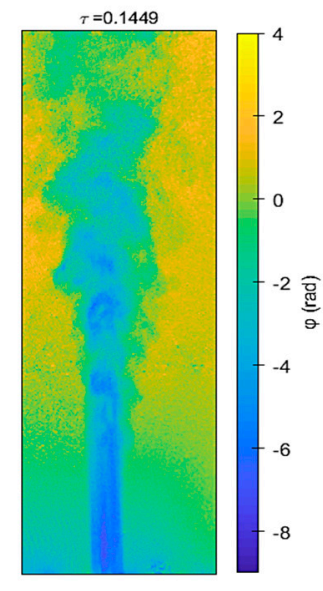

(e)

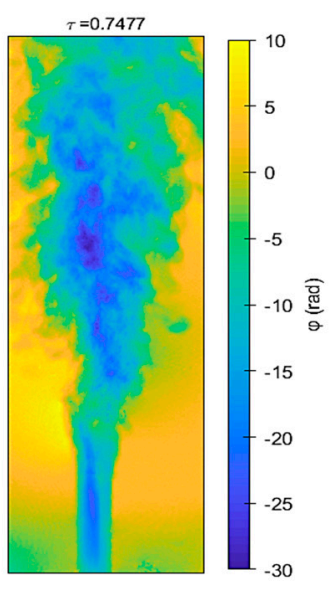

(j)

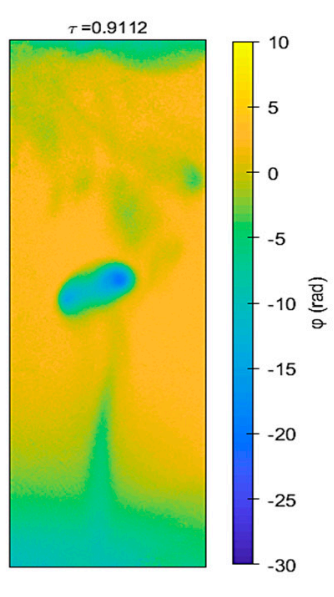

(o)

Figure 5. (a-o) Time evolution of the jet phase profile. 


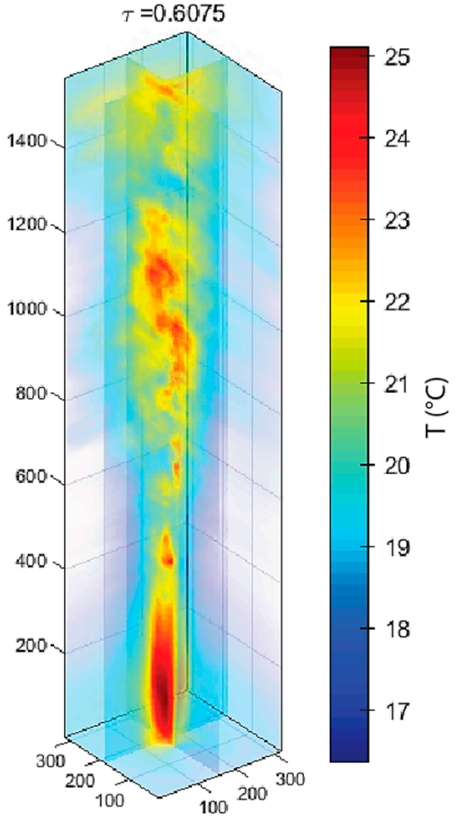

(a)

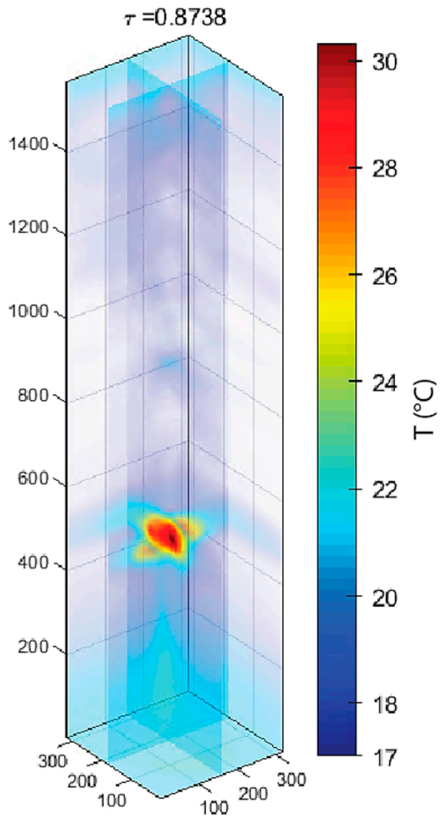

(b)

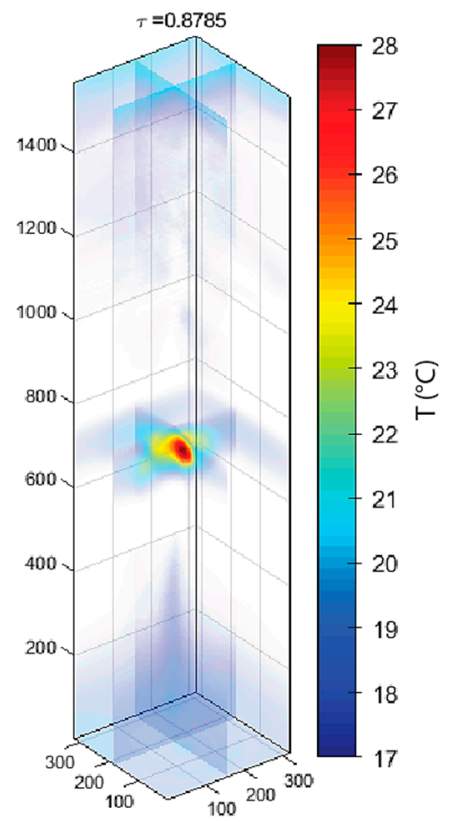

(c)

Figure 6. (a-c) Tomographic reconstruction at three different instants.

However, the condition on symmetry is not fully met. The averaging of many phase fields during the steady flow stage, results in the suppression of the signal fluctuation (random) component. The averaged phase profile over 15 consecutive frames is shown in Figure 7 . The averaging time is $1.47 \mathrm{~s}$ and thus faster random components are suppressed.

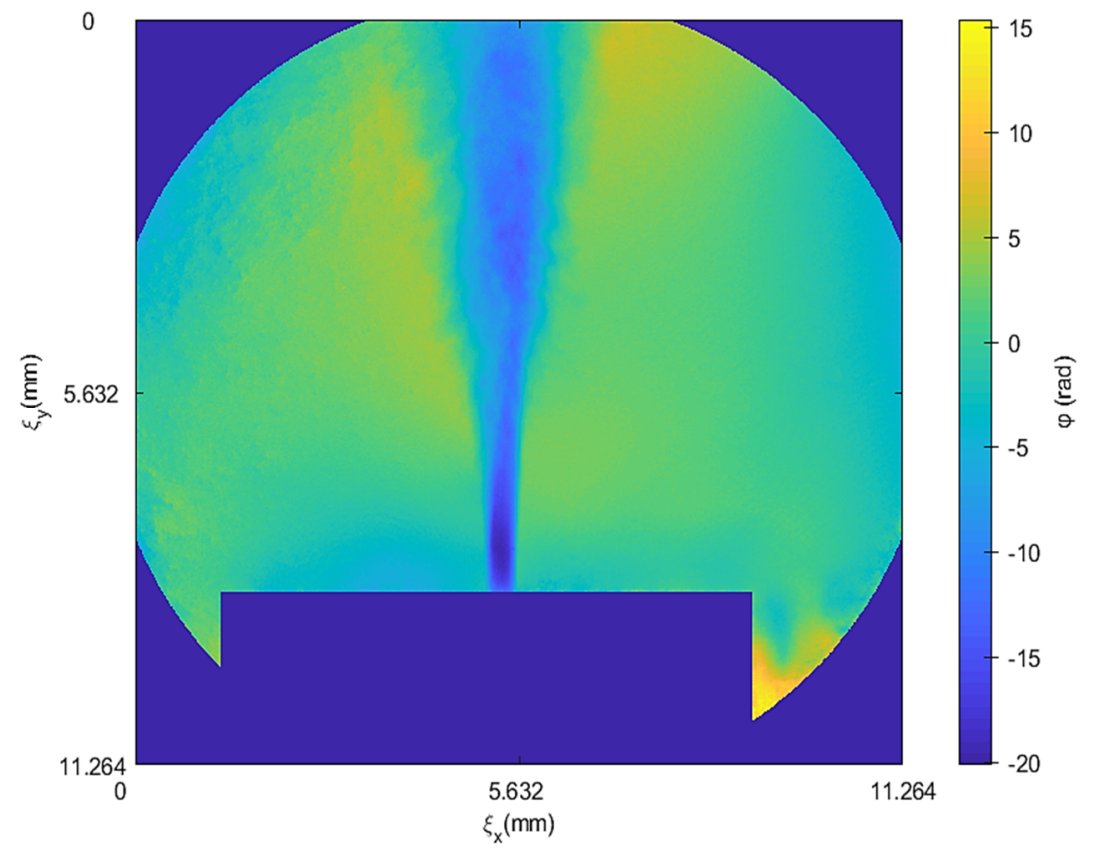

Figure 7. Averaged whole-field phase profile.

Figure 8 shows the tomographic reconstruction from the averaged phase values (see Figure 6 a for comparison). 


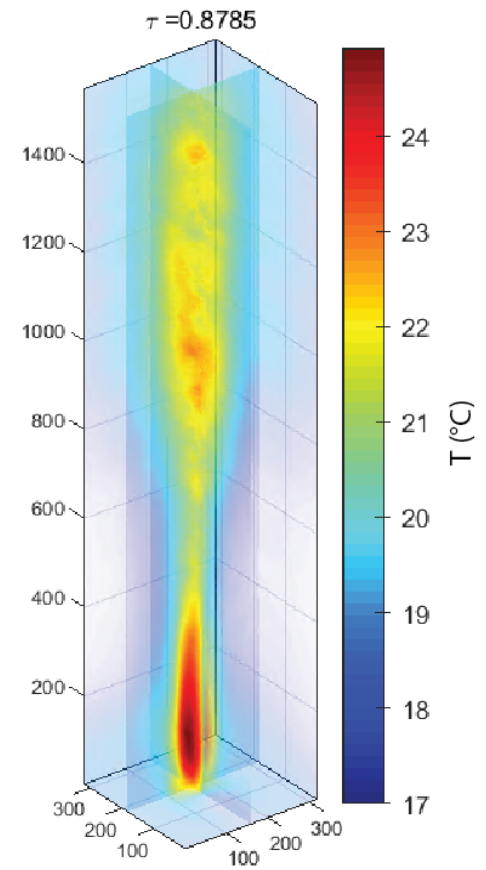

Figure 8. Tomographic reconstruction of the averaged phase profile.

In order to observe the thermal phenomena happening in the liquid in more detail, the dynamic range of the temperature values must be reduced. Therefore, temporal finite difference temperature $\dot{T}(n \Delta t)$ is computed. It has been computed as:

$$
\dot{T}(x, y, n \Delta t)=\frac{T(x, y, n \Delta t)-T(x, y,(n-1) \Delta t)}{\Delta t} .
$$

Fluid mixing can be seen on the first row of images of Figure 9. Where colder water from the tank is shown in blue color being pulled and mixed with warmer water, shown with yellowish color. The second row depicts the small warm water pocket traveling upward once the flow through the circular orifice was stopped. As seen, if the speed of the camera is high enough, this technique allows for its tracking.

\section{Limits and Errors of Interferometry in Liquids}

Several sources of error that are influencing our measurement are considered. Fundamentally, DHI measures interference phase $\Delta \varphi$, which is further converted into refractive index variation and in the last step the temperature change is determined, assuming $\frac{d n}{d T} \sim-1 \times$. Each of these steps suffer from some uncertainties.

The uncertainty of interference phase measurement comes from factors such as misalignment and settling of optical components, fluctuation of laser wavelength, electronic noise, and external unstable environment conditions [15]. The phase noise for our measurement is estimated to be $0.05 \mathrm{rad}$. The value was determined from experimental data (without the phenomenon) as the peak-to-valley value of an unwrapped phase map after low order polynomial subtraction (i.e., high spatial frequency components were considered as the noise). Such phase error contributes to temperature measurement uncertainty $\sim 0.01{ }^{\circ} \mathrm{C}$. However, the major uncertainty source is in the second step, i.e., the refractive index distribution calculation using inverse Abel transform. 


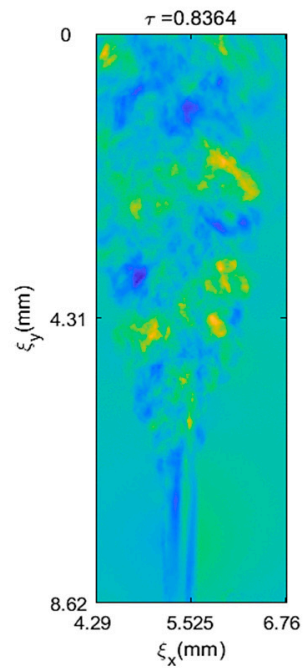

(a)

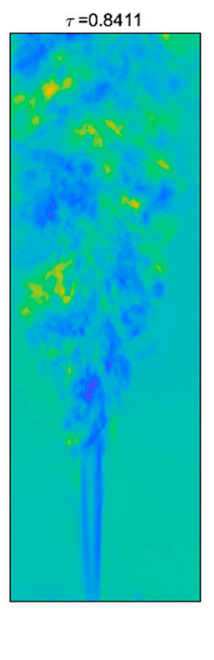

(b)

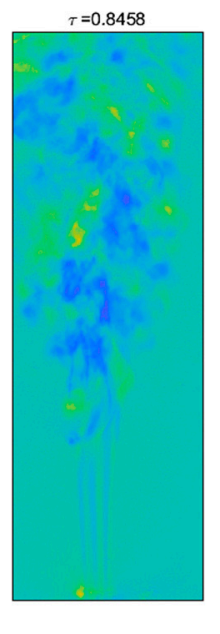

(c)

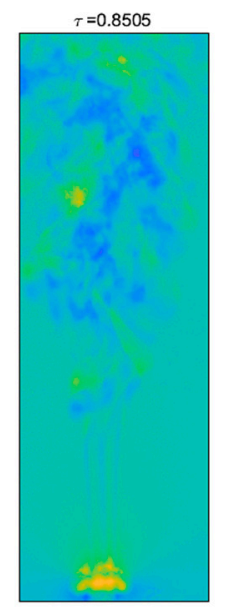

(d)

(e)

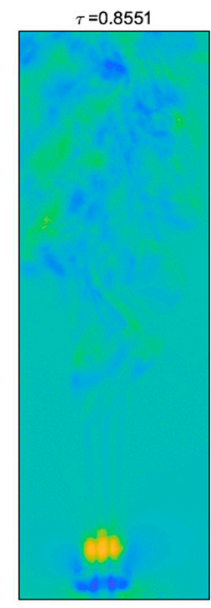

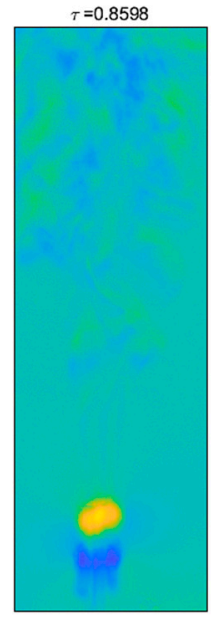

(f)

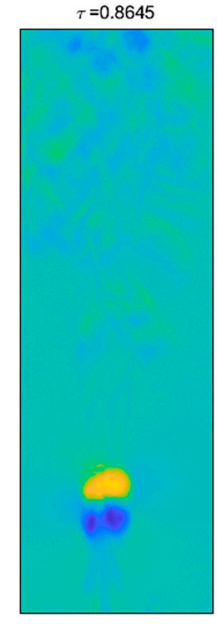

(g)

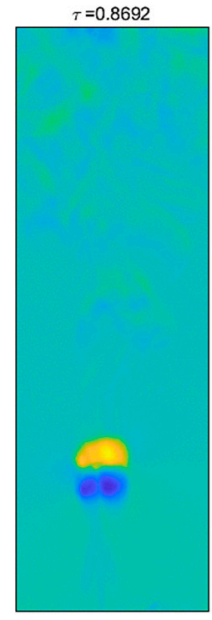

(h)
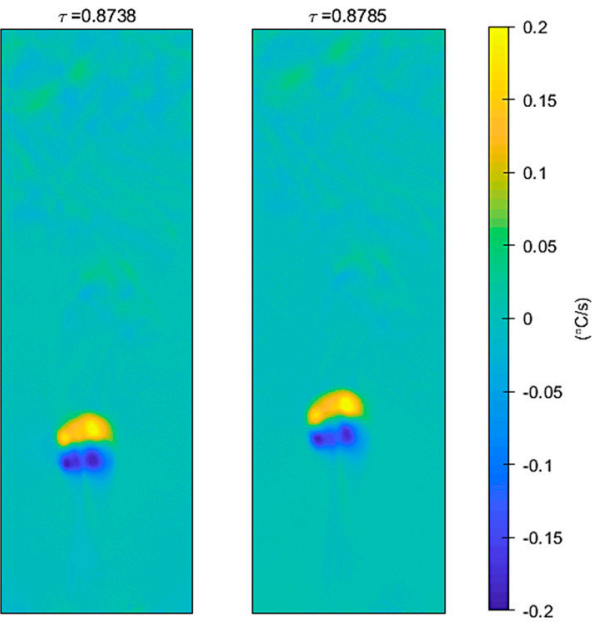

(j)

Figure 9. (a-j) Temporal finite difference temperature for different instants.

We assumed weakly-varying refractive index with the approximation of straight rays. Analysis $[55,56]$ revealed that even if a diffraction of light is considered, the refractive index uncertainty is always about one order lower than the measured variation of refractive index. However, this is valid for purely symmetrical fields or asymmetrical fields using many projections. Hence, the major source of uncertainty in our case is the assumption of symmetrical field even though the physical field evinces some random fluctuations. In order to estimate validity of the assumption, standard deviation of phase fields during the steady stage of the PJ was calculated as:

$$
\sigma(n, m)=\sqrt{\frac{1}{N} \sum_{i=1}^{N}\left(\Delta \varphi_{i}(n, m)-\overline{\Delta \varphi_{l}}(n, m)^{2}\right)}
$$

where $\overline{\Delta \varphi_{l}}$ is the averaged phase, and $N=13$ is the number of phase maps.

The standard deviation map of interference phase maps has been calculated and shown in Figure 10, where (a) shows the averaged phase map and (b) shows the standard deviation map. Two regions for evaluation have been selected: one further away in the 
developed area where the random flow fluctuations are more obvious and one near the opening where almost laminar flow is predicted. The estimated error in the region of the developed puff is $u_{\Delta \varphi}=1.56$ rad while in the region near the orifice the standard deviation is $u_{\Delta \varphi}=0.7 \mathrm{rad}$.

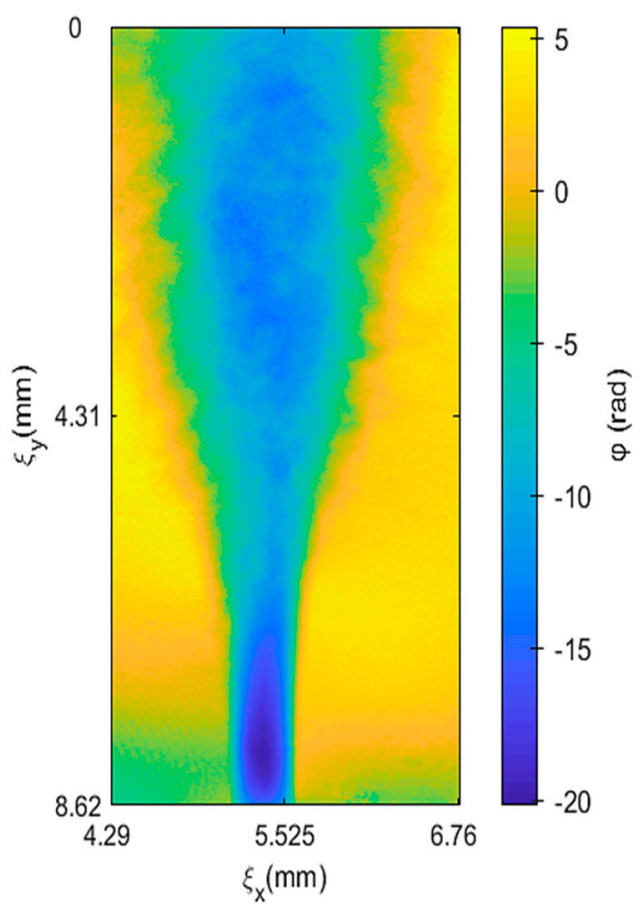

(a)

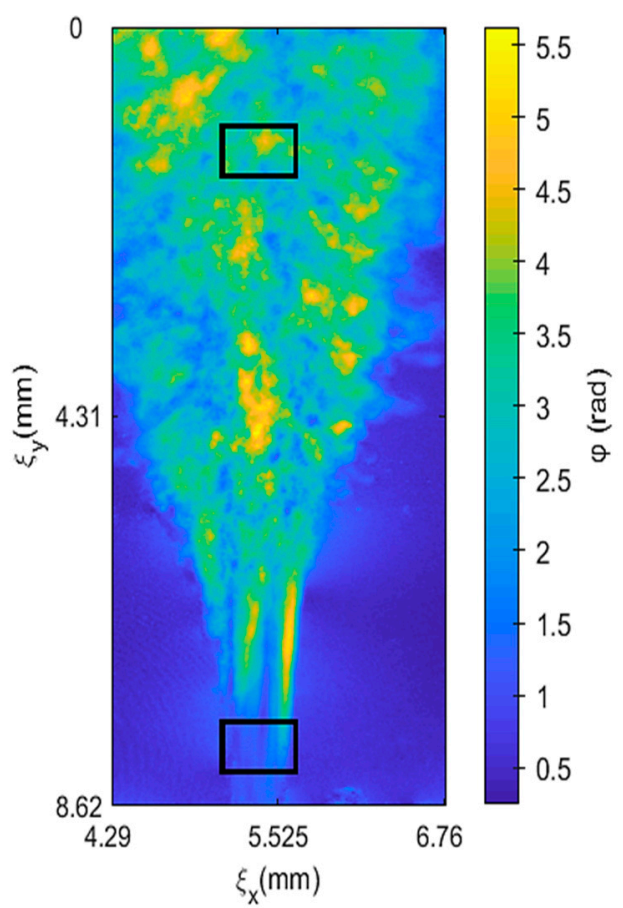

(b)

Figure 10. (a) Averaged phase map, (b) standard deviation.

From Figure 10 it follows that the assumption on symmetry is the main uncertainty source (one order higher than the aforementioned sources). Assuming flat (2D) field for simplification, the temperature uncertainty can be estimated as $u_{T}=\frac{\lambda}{2 \pi} \frac{u_{\Delta \varphi}}{L \cdot 1 \times 10^{-4}}$, where $L=4 \mathrm{~mm}$ is the orifice diameter. The uncertainty $u_{T}$ near the PJ opening is $0.03^{\circ} \mathrm{C}$, which is relatively below $5 \%$. On the other hand, further from the opening, where the random fluctuations play a more significant role $u_{T} \sim 0.6{ }^{\circ} \mathrm{C}$, it is relatively about $15 \%$.

In case of steady flow, averaging of phase maps can filter out the random fluctuations and hence decrease the uncertainty. On the other hand, many phenomena are rapidly time varying, averaging cannot be applied, and the uncertainty ranges are deduced in the range $5-20 \%$.

To verify the reliability of DHI we compared the results to results of well-established CTA (Constant Temperature Anemometry). CTA is single point method and therefore we chose one representative point within the measured area that was located on the axis of the orifice approximately $2 \mathrm{~mm}$ above the opening. Location of the CTA sensor is illustrated as a red cross in Figure 2. DHI is a full-field method and therefore we had to pick voxels of the measured temperature distribution corresponding to those values measured by CTA. Results showing a good agreement are plotted in Figure 11. The red color stands for DHI while blue represents values obtained by CTA. A significant source of the discrepancies in results between DHI and CTA is the fact that both measurements DHI and CTA had to be performed separately at different time due to invasive feature of CTA. Although the initial experimental parameters were set as similar as possible, the environmental conditions as well as behavior of the phenomenon itself could slightly vary between both measurements. 


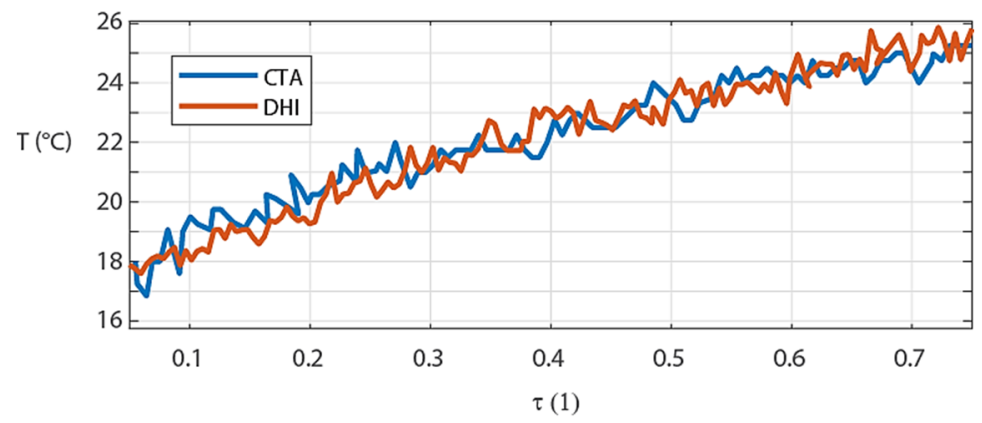

Figure 11. Comparison of DHI and CTA within one representative point within the measured area.

\section{Conclusions}

A digital holographic interferometric methodology for the measurement of temperature fields through the analysis of the refractive index variation has been implemented. Real-time dynamic temperature field change and visualization of volumetric temperature fields generated by a heated fluid from a pulsatile jet in a water tank through off-axis digital holographic interferometry have been reported. This paper, through the conducted experiment and results, presents and puts off-axis Digital Holographic Interferometry as a powerful technique to visualize symmetrical temperature fields in water created by a periodic pulsatile jet.

The pulsatile jet generator was placed in a water tank filled with water at room temperature. A pulsatile jet with higher temperature was coming out of the orifice with a circular diameter of $4 \mathrm{~mm}$. A portable Mach-Zehnder interferometer has been used in order to record the holograms with a digital camera. Digital holograms have been evaluated and symmetrical temperature fields have been retrieved using inverse Abel transform.

The main source of uncertainty was the assumption of a symmetric field, although the flow shows turbulence and other asymmetries. Due to the steady flow behavior during the middle part of the period, we estimated that the relative uncertainty of the temperature field measurement near the orifice is below $5 \%$. On the other hand, further from the orifice, where random fluctuations play a more significant role, the relative uncertainty increases up to $15 \%$. This must be considered when using single-shot DHI for symmetrical pulsatile jets investigation.

Results obtained through this study demonstrate a successful appliance of this approach for temperature field measurement in pulsatile jets with water as the working fluid. Our study indicates that digital holographic interferometry can be used to visualize temperature fields, study flows and evaluate their characteristic quantities, and is superior to other conventional methods since it is a non-invasive whole-field technique that can be automated and deliver real time results with high temporal and spatial resolution.

Author Contributions: Formal analysis, V.L. and T.V.; funding acquisition, P.P. and P.D.; methodology, G.C. and P.P.; software, G.C. and P.P.; validation, G.C. and P.D.; writing-original draft, G.C.; writing-review and editing, P.P., P.D., V.L. and T.V. All authors have read and agreed to the published version of the manuscript.

Funding: We gratefully acknowledge the support of the Grant Program of the Technical University of Liberec (project number PURE-2020-3010). This research was also funded by SGS 21291 (Experimental, numerical and theoretical research in fluid- and thermo-mechanics).

Conflicts of Interest: The authors declare no conflict of interest. The funders had no role in the design of the study; in the collection, analyses, or interpretation of data; in the writing of the manuscript, or in the decision to publish the results.

\section{References}

1. Shakher, C. Interferometric Methods to Measure Temperature and Temperature Profile of Gaseous Flames. Available online: https:/ /www.academia.edu/27528711/Interferometric_methods_to_measure_temperature_and_temperature_profile_of_ gaseous_flames (accessed on 1 April 2021). 
2. Al-Azzawi, A. Light and Optics: Principles and Practices; CRC Press: Boca Raton, FL, USA, 2007.

3. Malacara, D. Optical Shop Testing; John Wiley \& Sons, Inc.: Hoboken, NJ, USA, 2007.

4. Koukourakis, N.; Jaedicke, V.; Adinda-Ougba, A.; Goebel, S.; Wiethoff, H.; Höpfner, H.; Gerhardt, N.C.; Hofmann, M.R. Depth-filtered digital holography. Opt. Express 2012, 20, 22636-22648. [CrossRef]

5. Lédl, V.; Psota, P.; Doleček, R.; Vít, T. Digital holographic setups for phase object measurements in micro and macro scale. EPJ Web Conf. 2015, 92, 01001. [CrossRef]

6. $\quad$ Picart, P. New Techniques in Digital Holography; John Wiley \& Sons, Inc.: Hoboken, NJ, USA, 2015.

7. Verma, S.; Joshi, Y.M.; Muralidhar, K. Optical Interferometers: Principles and Applications in Transport Phenomena; Nova Publishers: Hauppauge, NY, USA, 2012.

8. Waynant, R.W.; Ediger, M.N. Electro-Optics Handbook; McGraw-Hill Education: New York, NY, USA, 2000.

9. Pavelek, M. Interferometrický Výzkum Přestupu Tepla v Soustavě Vertikálních Desek: Teze Habilitační Práce; Vysoké učení technické v Brneě. Energetický ústav: Brno, Czech Republic, 2001.

10. Herman, C.; Kang, E. Experimental visualization of temperature fields and study of heat transfer enhancement in oscillatory flow in a grooved channel. Heat Mass Transf. 2001, 37, 87-99. [CrossRef]

11. Borjian, E.; Yousefi, T.; Ashjaee, M. Optical interferometry to investigate the heat transfer from a vertical cone under air jet impingement. Opt. Lasers Eng. 2015, 67, 205-211. [CrossRef]

12. Doleček, R.; Psota, P.; Lédl, V.; Vít, T.; Václavík, J.; Kopecký, V. General temperature field measurement by digital holography. Appl. Opt. 2013, 52, A319-A325. [CrossRef]

13. Psota, P.; Dančová, P.; Cubreli, G.; Lédl, V.; Vít, T.; Doleček, R.; Matoušek, O. Development and application of spatial carrier interferometry for whole field real-time investigation of temperatures in liquid media. Int. J. Therm. Sci. 2019, 145, 106029. [CrossRef]

14. Ashjaee, M.; Arzaghi, M.; Jarrahi, M.; Yousefi, T. Experimental and numerical study of free convection on an isothermal downward cone. Exp. Heat Transf. 2007, 20, 307-322. [CrossRef]

15. Narayan, S.; Singh, A.K.; Srivastava, A. Interferometric study of natural convection heat transfer phenomena around array of heated cylinders. Int. J. Heat Mass Transf. 2017, 109, 278-292. [CrossRef]

16. Psota, P.; Tang, H.; Pooladvand, K.; Furlong, C.; Rosowski, J.J.; Cheng, J.T.; Ledl, V. Multiple angle digital holography for the shape measurement of the unpainted tympanic membrane. Opt. Express 2020, 28, 24614. [CrossRef] [PubMed]

17. Pavelek, M. Vizualizacni Metody v Technice Prostredi; VUTIUM: Brno, Czech Republic, 2009.

18. Landsberg, G.S. Onmuka/Optika, 5th ed.; Hayka (Nauka): Moscow, Russia, 1976.

19. Bommareddi, R. Applications of Optical Interferometer Techniques for Precision Measurements of Changes in Temperature, Growth and Refractive Index of Materials. Technologies 2014, 2, 54-75. [CrossRef]

20. Brooker, G. Modern Classical Optics; Oxford University Press: Oxford, UK, 2014.

21. Goodman, J.W. Introduction to Fourier Optics, 2nd ed.; McGraw-Hill: New York, NY, USA, 1996.

22. Mokrý, P.; Psota, P.; Steiger, K.; Václavík, J.; Doleček, R.; Vápenka, D.; Lédl, V. Ferroelectric domain pattern in barium titanate single crystals studied by means of digital holographic microscopy. J. Phys. D Appl. Phys. 2016, 49, 255307. [CrossRef]

23. Blanche, P.A. Optical holography: Materials, Theory and Applications; Elsevier: Amsterdam, The Netherlands, 2019.

24. Psota, P.; Mokrý, P.; Lédl, V.; Stašík, M.; Matoušek, O.; Kredba, J. Absolute and pixel-wise measurements of vibration amplitudes using time-averaged digital holography. Opt. Lasers Eng. 2019, 121, 236-245. [CrossRef]

25. Pavelek, M.; Janotková, E.; Štětina, J. Vizualizační a Optické Měřicí Metody, 2nd ed.; Vysoké učení technické v Brně.Fakulta strojního inženýrství-Energetický ústav.Odbor termomechaniky a techniky prostředí: Brno, Czech Republic, 2007.

26. Lédl, V.; Psota, P.; Vojtíšek, P.; Doleček, R.; Mokrý, P. Holographic contouring and its limitations in nearly specularly reflecting surface measurement. In Proceedings of the Optics and Measurement Conference 2014, Liberec, Czech Republic, 7-10 October 2014; p. 94420Q.

27. Malacara, D. Óptica Básica; Fondo de Cultura Económica: Mexico City, Mexico, 2014.

28. Dančová, P.; Vít, T.; Lédl, V.; Trávníček, Z.; Doleček, R. Holographic Interferometry as a tool for visualization of temperature fields in air. Eng. Mech. 2013, 20, 205-212.

29. Vit, T.; Doleček, R.; Psota, P.; Travniček, Z. Perspectives in Holographic Interferometry. 2013. Available online: https: / / scholar. google.com/citations?user=ZBgL234AAAAJ\&hl=en (accessed on 31 March 2021).

30. Vít, T.; Lédl, V. Identification of the temperature field in pulsatile impinging flow. AIP Conf. Proc. 2010, 1281, 135-138. [CrossRef]

31. Sharma, S.; Sheoran, G.; Shakher, C. Digital holographic interferometry for measurement of temperature in axisymmetric flames. Appl. Opt. 2012, 51, 3228-3235. [CrossRef] [PubMed]

32. Kumar, M.; Shakher, C. Measurement of temperature and temperature distribution in gaseous flames by digital speckle pattern shearing interferometry using holographic optical element. Opt. Lasers Eng. 2015, 73, 33-39. [CrossRef]

33. Sharma, S.; Sheoran, G.; Shakher, C. Temperature measurement of axisymmetric flame under the influence of magnetic field using lensless Fourier transform digital holography. Appl. Opt. 2012, 51, 4554. [CrossRef]

34. Psota, P.; Dolečk, R.; Lédl, V.; Vít, T.; Mokrý, P.; Dančová, P. Validation of digital holographic tomography in flow measurement. EPJ Web Conf. 2017, 143, 02097. [CrossRef]

35. Olchewsky, F.; Essaïdi, Z.; Desse, J.; Champagnat, F. 3D reconstructions of jets by multidirectional digital holographic tomography. In Proceedings of the 18th International Symposium on Flow Visualization, Zurich, Switzerland, 26-29 June 2010. [CrossRef] 
36. Sallam, K.A.; Lin, K.C.; Carter, C.D. Spray structure of aerated liquid jets using double-view digital holography. In Proceedings of the 48th AIAA Aerospace Sciences Meeting Including the New Horizons Forum and Aerospace Exposition, Orlando, FL, USA, 4-7 January 2010.

37. Guerrero-Mendez, C.; Anaya, T.S.; Araiza-Esquivel, M.; Balderas-Navarro, R.E.; Aranda-Espinoza, S.; López-Martínez, A.; OlveraOlvera, C. Real-time measurement of the average temperature profiles in liquid cooling using digital holographic interferometry. Opt. Eng. 2016, 55, 121730. [CrossRef]

38. Colombani, J.; Bert, J. Holographic interferometry for the study of liquids. J. Mol. Liq. 2007, 134, 8-14. [CrossRef]

39. Hossain, M.M.; Shakher, C. Temperature measurement in laminar free convective flow using digital holography. Appl. Opt. 2009, 48, 1869-1877. [CrossRef]

40. Alaswad, Z. Experimental and Numerical Study of a Synthetic Jet Ejector; University of Windsor: Windsor, ON, Canada, 2019.

41. Janotkova, E.; Pavelek, M. Determination of air outlet C-values by means of interferometry. Int. J. Vent. 2006, 4, 311-321. [CrossRef]

42. Broučková, Z.; Hsu, S.S.; Wang, A.B.; Trávníček, Z. Water Synthetic Jet Driven by a Piezoelectric Actuator-LIF and PIV Experiments. Adv. Mater. Res. 2015, 1104, 45-50. [CrossRef]

43. Mohseni, K.; Mittal, R. Synthetic Jets: Fundamentals and Applications; CRC Press: Boca Raton, FL, USA, 2014.

44. Amitay, M. Synthetic jets and their applications for fluid/thermal systems. Solid Mech. Appl. 2008, 7, 77-93. [CrossRef]

45. Li, S. A Numerical Study of Micro Synthetic Jet and Its Applications in Thermal Management; Georgia Institute of Technology: Atlanta, GA, USA, 2005.

46. Tensi, J.; Boué, I.; Paillé, F.; Dury, G. Modification of the wake behind a circular cylinder by using synthetic jets. J. Vis. 2002, 5, 37-44. [CrossRef]

47. Li, J.; Zhang, X. Active flow control for supersonic aircraft: A novel hybrid synthetic jet actuator. Sens. Actuators A Phys. 2020, 302, 111770. [CrossRef]

48. Weltmann, K.D.; Kolb, J.F.; Holub, M.; Uhrlandt, D.; Šimek, M.; Ostrikov, K.; Hamaguchi, S.; Cvelbar, U.; Černák, M.; Locke, B. The future for plasma science and technology. Plasma Process. Polym. 2019, 16, 1800118. [CrossRef]

49. Gillespie, M.B.; Black, W.Z.; Rinehart, C.; Glezer, A. Local Convective Heat Transfer From a Constant Heat Flux Flat Plate Cooled by Synthetic Air Jets. J. Heat Transf. 2006, 128, 990-1000. [CrossRef]

50. Trávníček, Z.; Tesař, V.; Broučková, Z.; Peszyński, K. Annular impinging jet controlled by radial synthetic jets. Heat Transf. Eng. 2014, 35, 1450-1461. [CrossRef]

51. Dancova, P.; Psota, P.; Vit, T. Measurement of a temperature field generated by a synthetic jet actuator using digital holographic interferometry. Actuators 2019, 8, 27. [CrossRef]

52. Broučková, Z. Synthetic and Continuous Jets Impinging on a Circular Cylinder: Flow Field and Heat Transfer Experimental Study; Czech Technical University in Prague: Prague, Czech Republic, 2018.

53. Kreis, T. Handbook of Holographic Interferometry: Optical and Digital Methods; Wiley: Hoboken, NJ, USA, 2004.

54. Venema, T.M.; Schmidt, J.D. Optical phase unwrapping in the presence of branch points. Opt. Express 2008, 16, 6985-6998. [CrossRef] [PubMed]

55. Gorski, W. Tomographic microinterferometry of optical fibers. Opt. Eng. 2006, 45, 125002. [CrossRef]

56. Wilkie, D.; Fisher, S.A. Measurement of Temperature by Mach-Zehnder Interferometry. Proc. Inst. Mech. Eng. 1963, 178, 461-470. [CrossRef] 